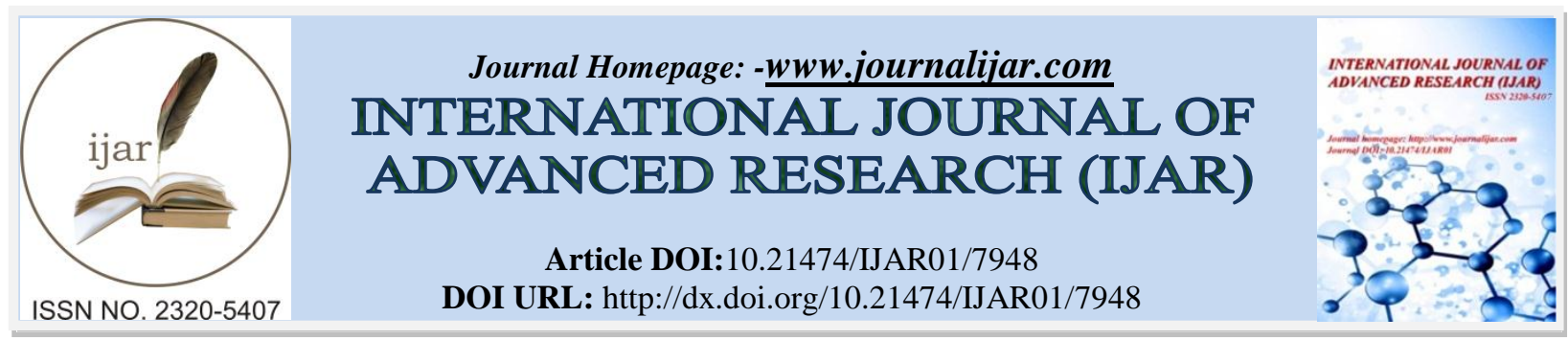

RESEARCH ARTICLE

\title{
BIOSYNTHESIS OF SILVER NANOPARTICLES USING MALUS DOMESTICA LEAF EXTRACT AND ITS BIOLOGICAL APPLICATIONS AGAINST HUMAN PATHOGENS.
}

\author{
Shantanu Raikar, ${ }^{3}$ Chetan J. D. ${ }^{3}$, Mangesh S. Jadhav, ${ }^{1}$ Sameer Kulkarni, ${ }^{1}$ P. U. Raikar, ${ }^{2}$ U. S. Raikar ${ }^{1}$ and \\ Shyam Kumar Vootla ${ }^{3}$. \\ 1. Department of Physics, Karnatak University Dharwad - 580003, Karnataka, India. \\ 2. Visvesvaraya Technological University, Machhe-590018, Belagavi, Karnataka, India . \\ 3. Department of Biotechnology and Microbiology Karnatak University Dharwad - 580003, Karnataka, India.
}

\section{Manuscript Info}

………………….

Manuscript History

Received: 16 August 2018

Final Accepted: 18 September 2018

Published: October 2018

Keywords:-

Biosynthesis. Malus domestica.

Escherichia coli. Staphylococcus aureus.

Silver NPs..

\section{Abstract}

The silver nanoparticles were synthesized by employing a green Malus domestica leaf extract assisted process. The synthesized nanoparticles were analyzed using the instruments FTIR, UV-Vis, PXRD, AFM and SEM with EDS for chemical, structural and morphological studies. It is observed that the phytochemicals present in the leaf extract are responsible for the stable nature of synthesized nanoparticles. The green synthesized silver nanoparticles have shown effective radical scavenging as well as antibacterial activities. From our current findings that the synthesized nanoparticles showing growth inhibitory activities against both gram positive and gram negative pathogenic bacteria, we can say that the synthesized nanoparticles can be used in medicine as the therapeutic agents.

Copy Right, IJAR, 2018,. All rights reserved.

\section{Introduction:-}

In recent decades as Feynman once said there is plenty of room at the bottom although he didn't mean Nanotechnology the area has been very fascinating lots of research work is going to explore possible various applications of nanoparticles (Cao, 2004; Kimling, 2006; Iravani, 2011;). Various approaches have been explored to synthesize nanoparticles broadly classified into bottom up and top down processes (Cao, 2004; Kavitha et al. 2013). The green synthesis of nanoparticles using leaf extract has been attracting scientific community because of environmentally benign, cost effective nature. The constituting of green method for the synthesis of silver nanoparticles is an important aspect of nano research. Syntheses of metal nanoparticles using different methods have been reported so far. Biosynthesis of metal nanoparticles using algae, plant leaves, stem, flowers, and bacteria are some new approach in synthesis (Hutchison, 2008; Links, 2011). This synthesis method is environment friendly, non- toxic, reliable, low cost and synthesized nanoparticles have various applications. The noble metal nanoparticles like $\mathrm{Au}, \mathrm{Ag}$, and Pt and their composites have been synthesized for various applications like sensor, solar cell, catalysis and biomedical (Bar et al. 2009; Iravani, 2011). Silver nanoparticles were synthesized using various methods for enormous applications. Among which green synthesized silver nanoparticles play a significant important role in biomedical field due to its unique physiochemical properties like high surface to volume ratio, surface Plasmon resonance in visible region and reactivity towards bacterial cell wall. The silver nanoparticles have shown good antibacterial activity against both gram positive as well as gram negative bacteria like Staphylococcus aureus and Escherichia coli (Tabassum et al. 2015). Numerous works have been published on the anti bacterial activity of Silver nanoparticles. 
Owing to the biomedical applications of silver nanoparticles and its composites towards antibacterial, antifungal, anticancer and free radical scavenging activities, here in this communication we report synthesis of bio friendly Silver nanoparticles using simple cost effective Malus domestica leaf extract mediated green process (Huang et al. 2007; Kulkarni et al. 2017; Jadhav et al. 2018). The synthesized nanoparticles are subjected to UV-Vis, FTIR, XRD, AFM and SEM with EDS to study physical, compositional, structural and morphological nature of the nanoparticles. The synthesized silver nanoparticles have shown good antibacterial activity against both gram positive ( $S$. aureus) as well as gram negative (E. coli) bacteria (Liu et al. 2002). The free radical scavenging activity has been evaluated for synthesized silver nanoparticles.

\section{Materials And Methods:- Materials:-}

Malus domestica leaves collected from Shimla, Silver nitrate $\left(\mathrm{AgNO}_{3}\right)$ of analytical grade purchased from Hi-media, double distilled water, whattman's filter paper No. 4, etc. All chemicals used without further purification.

\section{Preparation of leaf extract:-}

In order to prepare plant leaves extract, Malus domestica leaves were washed twice with double distilled water, dried and $20 \mathrm{~g}$ of Malus domestica leaves were chopped and dissolved in $50 \mathrm{~mL}$ of water kept at $80{ }^{\circ} \mathrm{C}$ for an hour until change in color of the sample. Formation of extract is confirmed by change in the color of the solution binary mixture. Obtained extract was filtered with whattman's filter paper No.4 to separate out the broth twice to get pure extract (Jadhav et al. 2018).

\section{Synthesis of silver nanoparticles:-}

Typical reaction procedure for the formation of $\mathrm{Au}$ nanoparticles is performed in aqueous medium. $0.01 \mathrm{M} \mathrm{of} \mathrm{AgNO}_{3}$ were taken and dissolved in $5 \mathrm{~mL}$ of deionized water and kept for some time to form a binary mixture of it and kept under $70{ }^{\circ} \mathrm{C}$ with constant stirring for $15 \mathrm{~min}$. The Malus domestica leaf extract was added drop wise until it shows change in the color from colorless to dark yellow. Change in color confirms the formation of Ag nanoparticles (Martinez-Castanon et al. 2008; Bar et al. 2009; Nabikhan et al. 2010). Ag nanoparticles centrifuged several times and washed to get impurities free Ag nanoparticles colloidal solution, then dried up to formation of dry powder sample. Obtained Ag particles are used for further characterization to study surface morphology, particle size, functional group, elemental analysis etc. through different techniques.

\section{Characterization Techniques:-}

The surface Plasmon resonance is observed using UV-Vis spectra (UV-Vis spectrophotometer, Ocean Optics, HR4000). Crystalline nature data is gathered using X-ray diffractometer (Rigaku) with $\mathrm{Cu} \mathrm{K} \alpha=1.54178 \AA$ over the $2 \theta$ angles ranging from $20^{\circ}-80^{\circ}$. FTIR-spectra of the silver nanoparticles were recorded in the range of $400-4000$ $\mathrm{cm}^{-1}$ using a NICOLET 6700, USA instrument. . The shape, size and elemental analysis of the nanoparticles was investigated using SEM with EDX (JEOL JSM-6360, Mira-3, Tescan, Brno-Czech Republic). The size of the synthesized nanoparticles was studied using atomic force microscopy (AFM) (Cao, 2004; Huang et al. 2007).

\section{Agar well diffusion method:-}

The antibacterial activity of the green synthesized silver nanoparticles was determined using the Agar Well diffusion method (Khan et al. 2016; Kulkarni et al. 2017; Jadhav et al. 2018). Lag phase cultures of gram positive bacteria $S$. aureus and gram negative bacteria $E$. coli were used as the test microorganisms. $100 \mathrm{~mL}$ of the test organisms were swab inoculated onto sterile nutrient agar petriplates for bacteria and 4 wells were bored. Different concentrations $(20,40,60,80$ and $100 \mu \mathrm{g} / \mathrm{mL}$ in sterile distilled water) of the synthesized silver nanoparticles were added to the labeled wells respectively. These plates were incubated at $37{ }^{\circ} \mathrm{C}$ for $24 \mathrm{~h}$ for bacteria culture followed by observing and measuring the antibacterial activity of the synthesized silver nanoparticles by measuring the zones of inhibition in millimeters using the scale.

\section{Evaluation of Antioxidant activity of Ag NPs by DPPH radical scavenging activity:-}

The antioxidant activity of the synthesized silver nanoparticles was measured on the basis of the free radical scavenging activity by the DPPH (1, 1- diphenyl 2-picrylhydrazyl) method (Mittal et al. 2012; Liaudanskas et al. 2014). The stock solution of DPPH. was prepared by dissolving $3.9432 \mathrm{mg} \mathrm{DPPH}$ in $100 \mathrm{~mL}$ of methanol (0.1 mM) and stored at $4{ }^{\circ} \mathrm{C}$ until use. $2 \mathrm{~mL}$ of DPPH solution was mixed with $1 \mathrm{~mL}$ of different concentrations (20 -100 $\mu \mathrm{g} / \mathrm{mL})$ of the synthesized silver nanoparticles. Ascorbic acid $(100 \mu \mathrm{g} / \mathrm{mL})$ was used as the reference standard. Mixer of $1 \mathrm{~mL}$ distilled water and $2 \mathrm{~mL}$ DPPH solution was used as the control. The reaction mixture was mixed 
and incubated at room temperature in the dark for $30 \mathrm{~min}$. The absorbance was recorded spectrophotometrically at $517 \mathrm{~nm}$.

The antioxidant activity of the synthesized nanoparticles was estimated based on the percentage of DPPH radical scavenged as the following equation (Tabassum et al. 2015):

$$
\text { Scavenging effect } \%=[\text { control absorbance }- \text { sample absorbance }] \times 100
$$

Control absorbance

Statistical analysis was carried out using SPSS software, version 20.0. The experiments were carried out in triplicates and the data was expressed as mean \pm standard deviation by One-Way ANOVA. Turkey's multiple comparison test was used to determine significant differences between the Standard and synthesized compounds. Correlation analysis was carried out using Pearson's correlation analysis using $\mathrm{p}=0.01$.

\section{Results And Discussion:-}

Malus domestica leaf extract assisted green synthesis of Silver nanoparticles is carried out. The synthesized nanoparticles have been characterized in terms of morphology, optical properties, structure, and crystallinity. Furthermore the antibacterial activity was evaluated against gram negative bacteria $(E$. coli) as well as gram positive bacteria (S. aureus). Free radical scavenging activity of synthesized silver nanoparticles has been carried out.

\section{FTIR studies:-}

FT-IR spectra were recorded to study the effective incorporation of extract on nanoparticles and presence of different functional groups in the nanocomposite material. In order to investigate the bond formation of nanoparticles FT-IR analysis is performed. FT-IR spectra of Malus domestica leaf, $\mathrm{CuO}$ and $\mathrm{Ag}-\mathrm{CuO}$ nanoparticles are as shown in Fig.1. $\mathrm{CuO}$ and $\mathrm{Ag}-\mathrm{CuO}$ nanoparticles obtained for each one of the solids reveals that there is a coordination of ligands in the solids. Broad band at $3426.12 \mathrm{~cm}^{-1}$ shows $\mathrm{N}-\mathrm{H}$ stretching for silver compound. Bands at $2924.19 \mathrm{~cm}^{-1}$ and $2854.95 \mathrm{~cm}^{-1}$ are attributed to the $\mathrm{C}-\mathrm{H}$ asymmetric and symmetric stretching respectively. Band at $1748.16 \mathrm{~cm}^{-1}$ shows carbonyl group due to photochemical present in extract. Whereas $1417.50 \mathrm{~cm}^{-1} \mathrm{C}-\mathrm{H}$ asymmetric bending, aqueous phase synthesis at $1374.33 \mathrm{~cm}^{-1}$ shows $\mathrm{O}-\mathrm{H}$ bending. Bands at $1203.60 \mathrm{~cm}^{-1}$ and $1155.53 \mathrm{~cm}^{-1}$ show C-H bending (aromatic in plane). Band at $1079.06 \mathrm{~cm}^{-1}$ shows C-C vibrations (Skeletal) and $932.86 \mathrm{~cm}^{-1} \mathrm{C}-\mathrm{H}$ bending (out of plane). $532.46 \mathrm{~cm}^{-1}$ shows C-I stretch in Aliphatic iodo compounds (Coates, 2000).

\section{Optical studies:-}

UV-Vis absorption spectroscopy has been developed as a preliminary tool to study the surface Plasmon resonance of metal nanoparticles. Fig. 2 shows the UV-Vis absorption spectra of the Silver nanoparticles. The synthesized colloidal nanoparticles show a surface plasmon resonance peak at $416 \mathrm{~nm}$ indicating the formation of Silver nanoparticles with $10-15 \mathrm{~nm}$ size (Huang et al. 2007; Vigneshwaran et al. 2006).

\section{XRD Analysis:-}

An X-ray diffraction analysis was carried out to study the crystallanity and grain size of the synthesized silver nanoparticles. The XRD spectrum of the synthesized silver nanoparticles is shown in figure.3. The XRD pattern shows the synthesized nanoparticles are having nano crystalline structure with Bragg reflections (111), (200), (220) and (311) corresponds to $2 \theta$ values of $38.02^{\circ}, 43.58^{\circ}, 64.32^{\circ}$ and $77.22^{\circ}$ respectively (Awwad and Salem, 2012). The average particle size of Malus domestica leaf extract mediated synthesis of silver nanoparticles can be calculated using Debye - Scherrer formula.

$$
\mathrm{D}=\mathrm{K} \lambda / \beta \cos \theta
$$

Where $\mathrm{D}=$ the crystallite size of green silver nanoparticles.

$\lambda=$ the wavelength of $x$-ray source $(1.542 \AA)$ used in XRD.

$\beta=$ the full width at half maximum of the diffraction peak.

$\mathrm{K}=$ the Scherrer constant with value 0.94 .

$\theta=$ the Bragg angle.

The Debye-Scherrer calculations show that the green synthesized silver nanoparticles have average grain size of $10 \mathrm{~nm}$. 


\section{Microscopic Analysis:-}

The Atomic force microscope (AFM) image (Fig.4) shows the synthesized nanoparticles are spherical in shape with average $15 \mathrm{~nm}$ diameter size particles. The fig.5 shows the SEM image showing the well dispersed silver nanoparticles of spherical shape having $10-15 \mathrm{~nm}$ size. The elemental analysis of synthesized silver nanoparticles is carried out using EDS fitted with SEM. The elemental analysis shows that indeed the synthesized nanoparticles are having the presence of $\mathrm{Ag}$ element indicating the formation of silver nanoparticles.

\section{Radical Scavenging Activity:-}

Free radical such as hydroxyl ions, are responsible for the faster cell decay of the healthy cells, so we performed free radical scavenging activity of the green synthesized silver nanoparticles taking ascorbic acid as the standard. The table. 1 shows the free radical scavenging activity of silver nanoparticles from where we can see that the $\mathrm{IC}_{50}$ for the silver nanoparticles is $55.73 \mu \mathrm{g} / \mathrm{mL}$ where as for ascorbic acid the $\mathrm{IC}_{50}$ value is 24.73 . Although the $\mathrm{IC}_{50}$ value of green silver nanoparticles is slightly more than that of the ascorbic acid but owing to the green nature of the silver nanoparticles compared to the ascorbic acid the synthesized nanoparticles are very much useful in case of free radical scavenging processes (Tabassum et al. 2015).

\section{Antibacterial Activity:-}

The antibacterial activity of synthesized green nanoparticles is evaluated using the $S$. aureus (gram positive) and $E$. coli (gram negative) as test samples which are multi drug resistant bacteria. The figure $6(\mathrm{a} \& \mathrm{~b})$ shows that the green silver nanoparticles exhibit excellent antibacterial activity against both gram positive ( $S$. aureus) and gram negative bacteria $(E$. coli). The zone of inhibition is shown in the table. 2 in that we can see that the green synthesized nanoparticles are more active towards $S$. aureus with an minimum inhibition concentration of about 25 $\mu \mathrm{g} / \mathrm{mL}$ while for $E$. coli the minimum inhibition concentration is about $50 \mu \mathrm{g} / \mathrm{mL}$. Although the action of silver nanoparticles on inhibition of bacteria is largely unknown but some of the researchers predict that the silver nanoparticles produce hydroxyl ions on the cell wall of the bacteria and penetrating through it and causing cell apoptosis leading to the inhibition of the bacteria.

\section{Conclusion:-}

We have successfully synthesized silver nanoparticles via Malus domestica leaf extract mediated process. The synthesized nanoparticles are capped by the phytochemicals present in the leaf extract indicated by the FTIR spectrum of the nanoparticles. The UV-Vis spectrum shows the formation of silver nanoparticles with the surface Plasmon resonance peak at $416 \mathrm{~nm}$. The synthesized nanoparticles are having crystalline structure as indicated by the XRD pattern. The analyses indicate the formation of silver nanoparticles with an average size of $15 \mathrm{~nm}$. The synthesized silver nanoparticles have shown excellent free radical activity and antibacterial activity. From our current findings that the synthesized nanoparticles showing growth inhibitory activities against both gram positive and gram negative pathogenic bacteria, we can say that the synthesized nanoparticles can be used in medicine as the therapeutic agents due to its antimicrobial activities against bacteria evaluated in vitro.

\section{Conflict of interest}

Authors do not have any conflict of interest related to the manuscript.

\section{Figures:-}

Fig.1:-FT-IR spectra of synthesized Ag nanoparticles

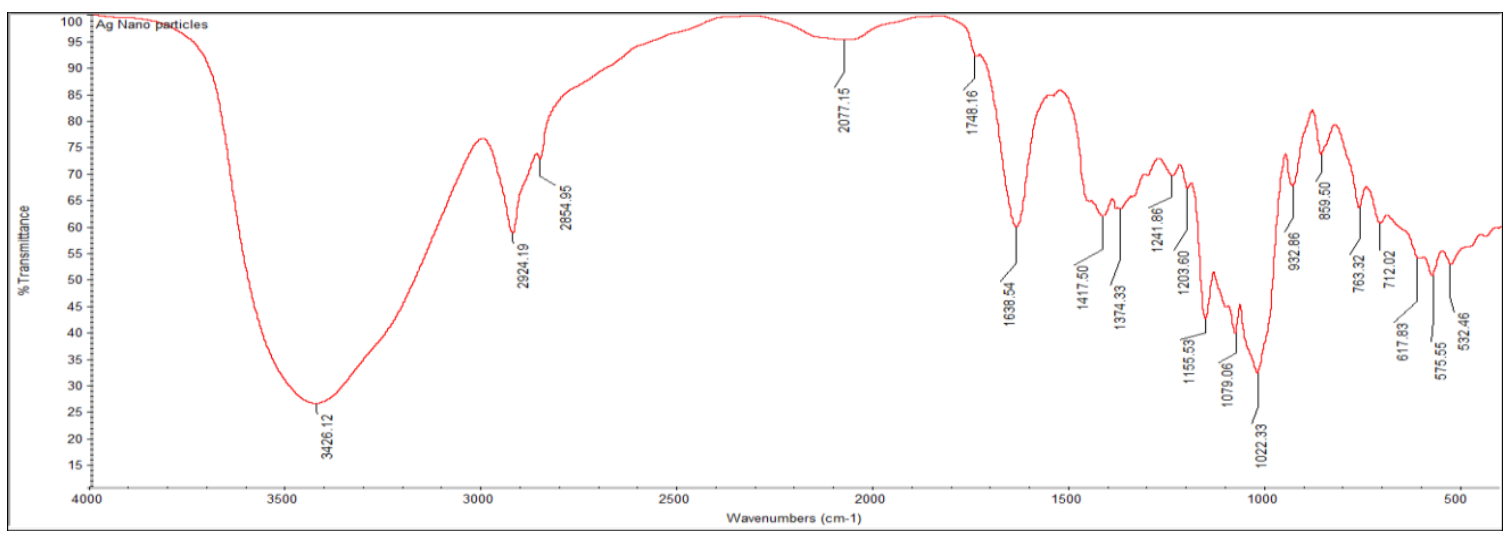


Fig.2:-UV-Visible absorption spectrum of Ag nanoparticles

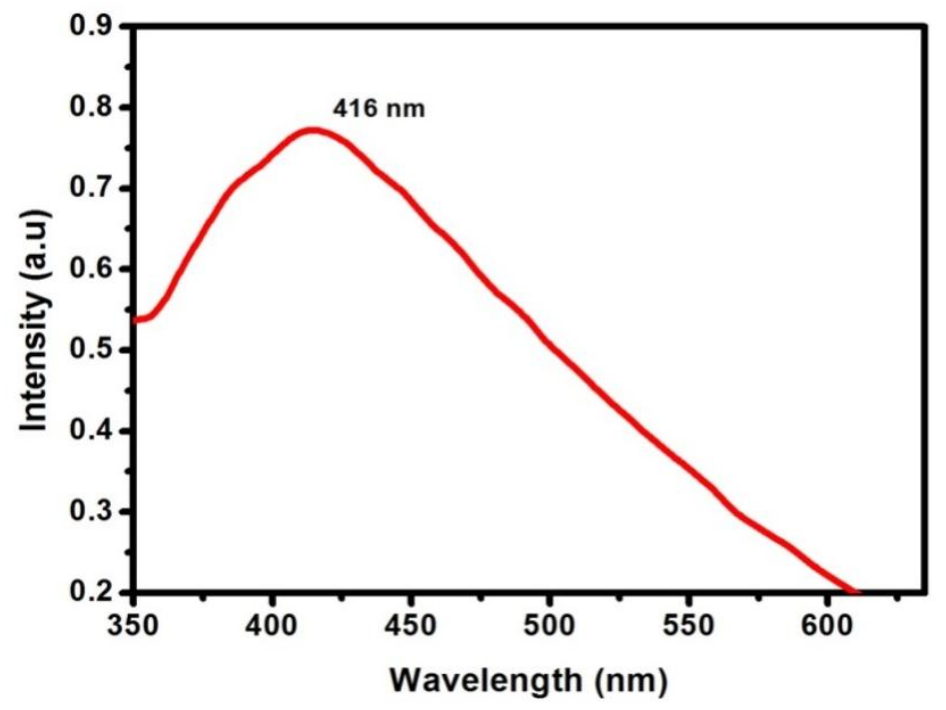

Fig 3:-XRD pattern of the silver nanoparticles

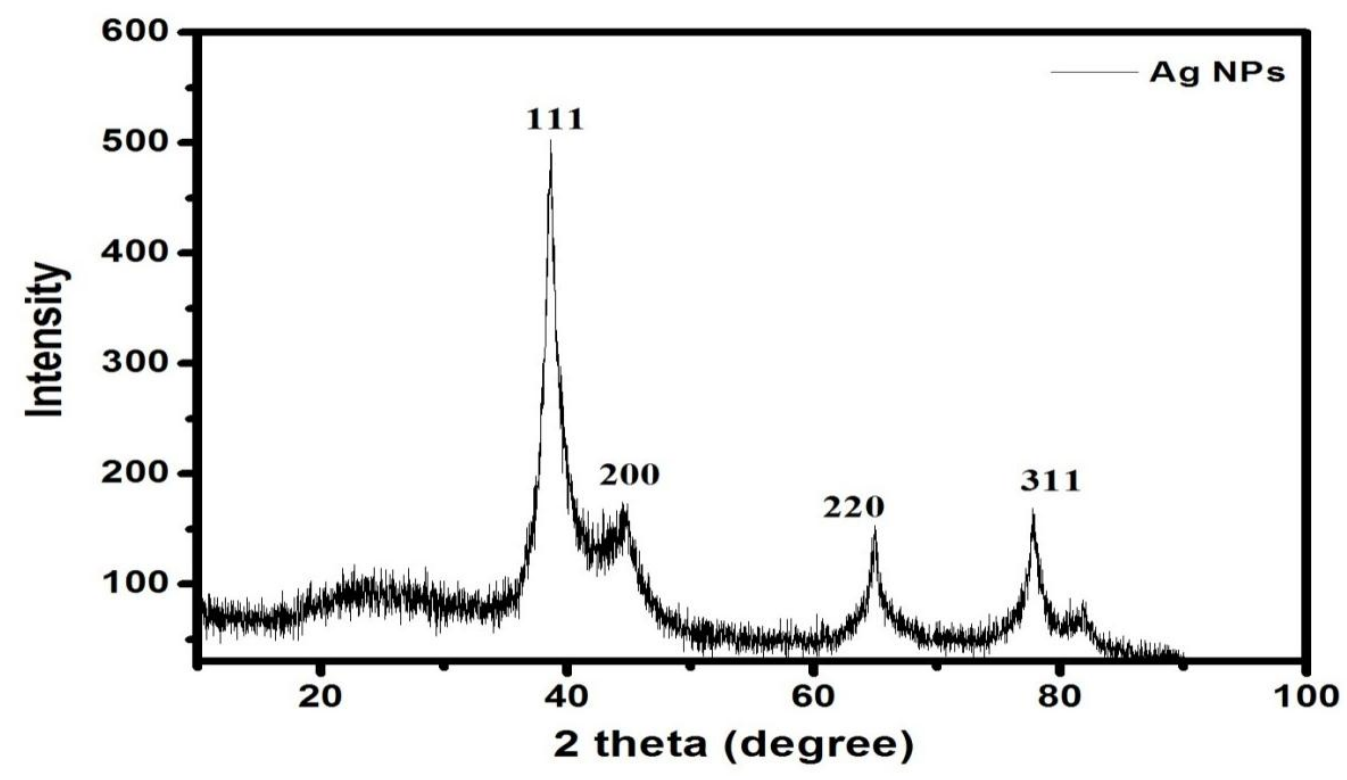

Fig.4: AFM images of Ag nanoparticles synthesized by molus domestics leaf extract

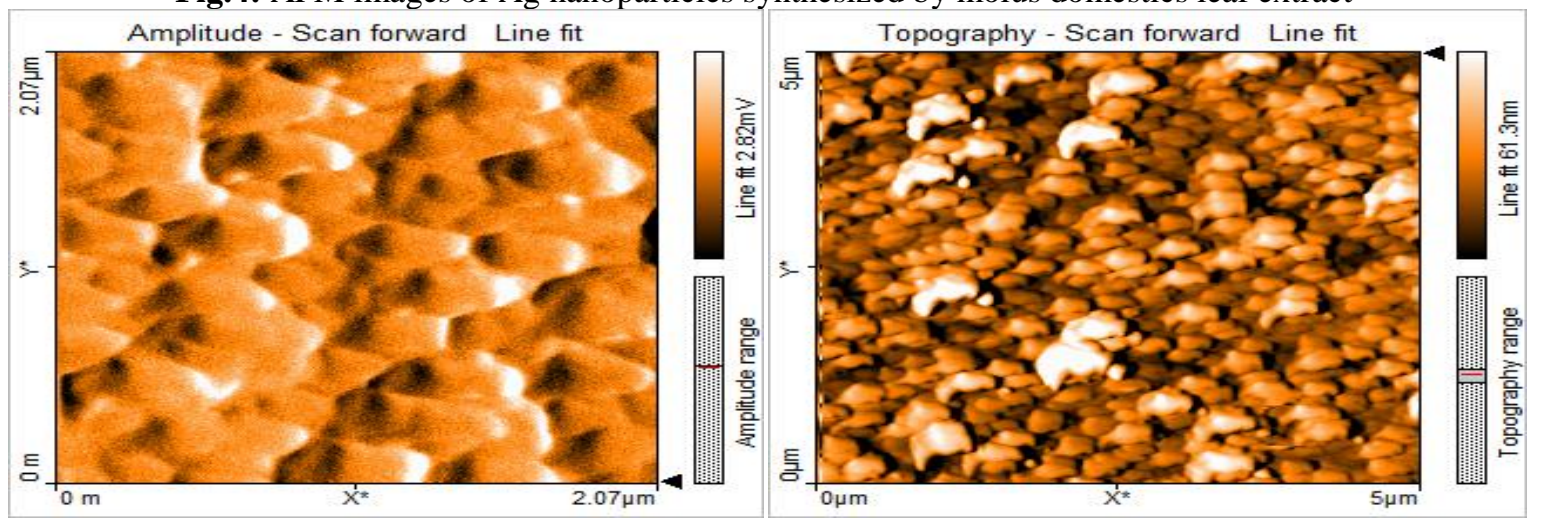


Fig.5:-SEM micrograph and EDS analysis of Ag nanoparticles
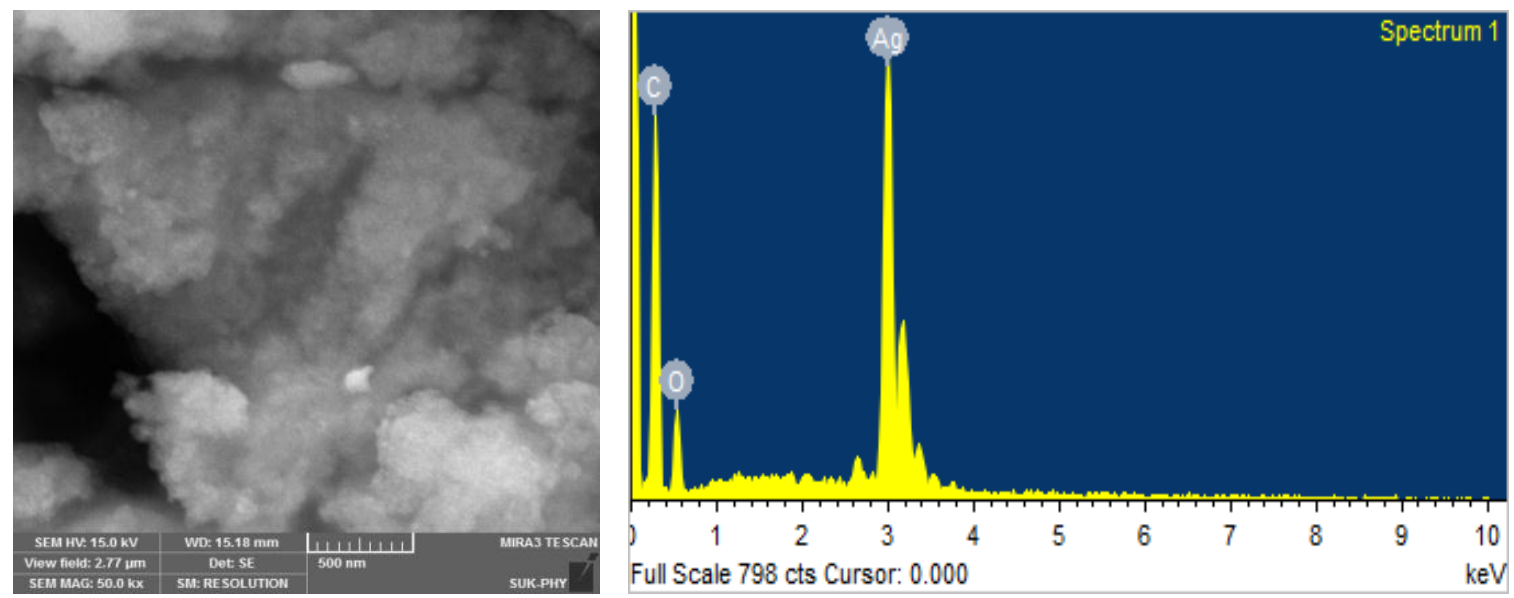

Fig.6:-Silver nanoparticles inhibiting the growth of a) S.aureus b) E.coli
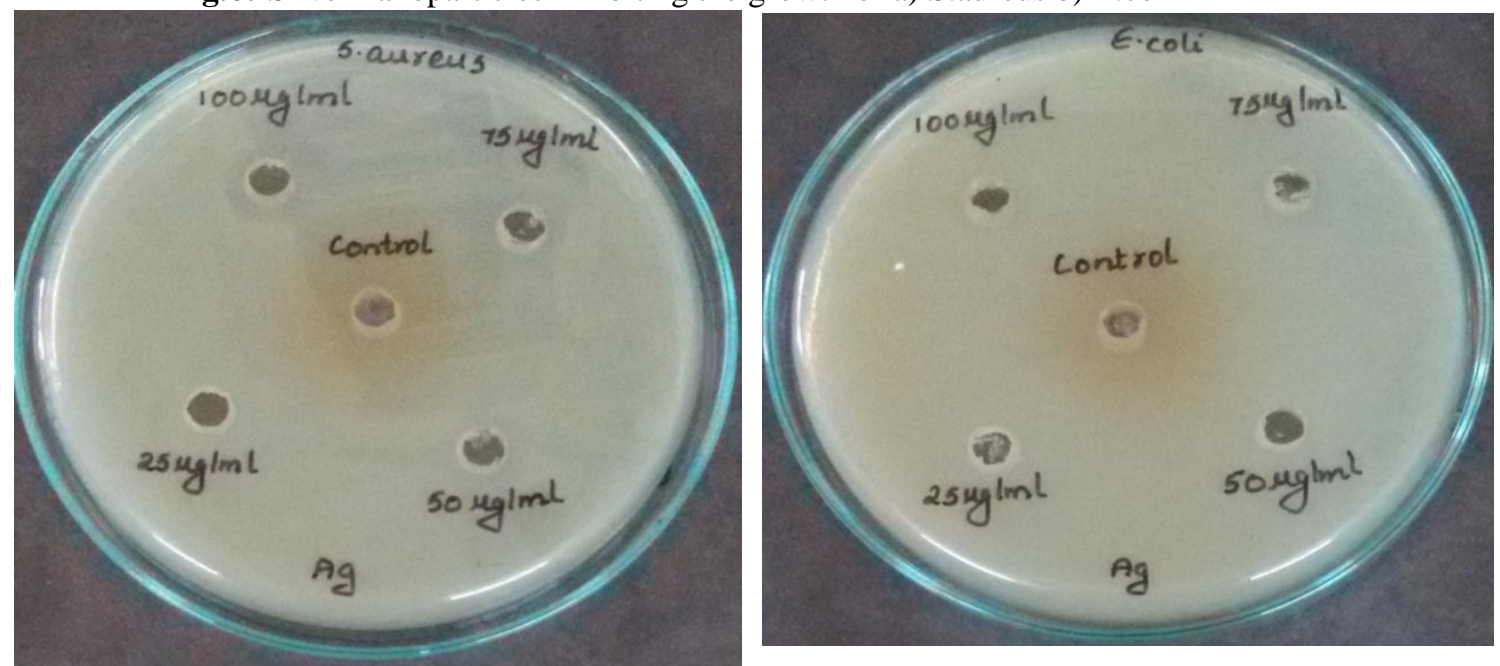

Table1:-Free radical scavenging activity of silver nanoparticles

\begin{tabular}{|c|c|c|}
\hline $\begin{array}{c}\text { Concentration in } \\
\boldsymbol{\mu g} / \mathbf{m L}\end{array}$ & \multicolumn{2}{|c|}{ Radical scavenging activity (\%) } \\
\cline { 2 - 3 } & Standard Ascorbic acid** & $\mathbf{A g}^{* *}$ \\
\hline 20 & $40.4333 \pm 2.24335$ & $26.5900 \pm 1.07056$ \\
\hline 40 & $58.2700 \pm 1.43419$ & $35.8900 \pm 2.44096$ \\
\hline 60 & $76.1633 \pm 2.75544$ & $52.6533 \pm 2.33504$ \\
\hline 80 & $84.9433 \pm 1.34031$ & $63.9600 \pm 2.60023$ \\
\hline 100 & $94.6133 \pm 0.90007$ & $78.3567 \pm 1.78892$ \\
\hline $\mathrm{IC}_{50}$ value & $24.73 \mu \mathrm{g} / \mathrm{mL}$ & $55.73 \mu \mathrm{g} / \mathrm{mL}$ \\
\hline
\end{tabular}

Table2:-Antimicrobial Assay of the Synthesized Ag Nanoparticles

\begin{tabular}{|c|c|c|}
\hline \multirow{3}{*}{ Concentration } & Staphylococcus aureus & Escherichia coli \\
\cline { 2 - 3 } & $\mathrm{Ag}$ & $\mathrm{Ag}$ \\
\cline { 2 - 3 } & Zone of Inhibition in $\mathrm{mm}$ & Zone of Inhibition in $\mathrm{mm}$ \\
\hline $25 \mu \mathrm{g} / \mathrm{mL}$ & 10 & - \\
\hline $50 \mu \mathrm{g} / \mathrm{mL}$ & 12 & 10 \\
\hline $75 \mu \mathrm{g} / \mathrm{mL}$ & 13 & 11 \\
\hline
\end{tabular}


\begin{tabular}{c|r|r}
$100 \mu \mathrm{g} / \mathrm{mL}$ & 14 & 14
\end{tabular}

\section{References:-}

1. Awwad, A. M., \& Salem, N. M. (2012). Green Synthesis of Silver Nanoparticles byMulberry LeavesExtract. Nanoscience and Nanotechnology, 2(4), 125-128.

2. Bar, H., Bhui, D. K., Sahoo, G. P., Sarkar, P., De, S. P., \& Misra, A. (2009). Green synthesis of silver nanoparticles using latex of Jatropha curcas. Colloids and surfaces A: Physicochemical and engineering aspects, 339(1-3), 134-139

3. Cao, G. (2004). Nanostructures \& nanomaterials: synthesis, properties \& applications. Imperial college press.

4. Coates, J. (2000). Interpretation of infrared spectra, a practical approach. Encyclopedia of analytical chemistry, 12, 10815-10837.

5. Huang, J., Li, Q., Sun, D., Lu, Y., Su, Y., Yang, X., ... \& Hong, J. (2007). Biosynthesis of silver and gold nanoparticles by novel sundried Cinnamomum camphora leaf. Nanotechnology, 18(10), 105104.

6. Hutchison, J. E. (2008). Greener nanoscience: a proactive approach to advancing applications and reducing implications of nanotechnology. vol. 2, no. 3, pp. 395-402

7. Iravani, S. (2011). Green synthesis of metal nanoparticles using plants. Green Chemistry, 13(10), $2638-2650$.

8. Jadhav, M. S., Kulkarni, S., Raikar, P., Barretto, D. A., Vootla, S. K., \& Raikar, U. S. (2018). Green biosynthesis of $\mathrm{CuO} \& \mathrm{Ag}-\mathrm{CuO}$ nanoparticles from Malus domestica leaf extract and evaluation of antibacterial, antioxidant and DNA cleavage activities. New Journal of Chemistry, 42(1), 204-213.

9. Kavitha, K. S., Baker, S., Rakshith, D., Kavitha, H. U., Yashwantha Rao, H. C., Harini, B. P., \& Satish, S. (2013). Plants as green source towards synthesis of nanoparticles. Int Res J Biol Sci, 2(6), 66-76.

10. Khan, A. U., Yuan, Q., Wei, Y., Khan, G. M., Khan, Z. U. H., Khan, S., ... \& Khan, F. U. (2016). Photocatalytic and antibacterial response of biosynthesized gold nanoparticles. Journal of Photochemistry and Photobiology B: Biology, 162, 273-277.

11. Kimling, J., Maier, M., Okenve, B., Kotaidis, V., Ballot, H., \& Plech, A. (2006). Turkevich method for gold nanoparticle synthesis revisited. The Journal of Physical Chemistry B, 110(32), 15700-15707.

12. Kulkarni, S., Jadhav, M., Raikar, P., Barretto, D. A., Vootla, S. K., \& Raikar, U. S. (2017). Green synthesized multifunctional Ag@ Fe 2 O 3 nanocomposites for effective antibacterial, antifungal and anticancer properties. New Journal of Chemistry, 41(17), 9513-9520.

13. Liaudanskas, M., Viškelis, P., Raudonis, R., Kviklys, D., Uselis, N., \& Janulis, V. (2014). Phenolic composition and antioxidant activity of Malus domestica leaves. The Scientific World Journal, 2014. pp. 1-10

14. Links, D. A. (2011). "Green Chemistry Green synthesis of metal nanoparticles using plants,". 2638-2650.

15. Liu, J., Zhang, T., Lu, T., Qu, L., Zhou, H., Zhang, Q., \& Ji, L. (2002). DNA-binding and cleavage studies of macrocyclic copper (II) complexes. Journal of inorganic biochemistry, 91(1), 269-276.

16. Martinez-Castanon, G. A., Nino-Martinez, N., Martinez-Gutierrez, F., Martinez-Mendoza, J. R., \& Ruiz, F. (2008). Synthesis and antibacterial activity of silver nanoparticles with different sizes. Journal of Nanoparticle Research, 10(8), 1343-1348.

17. Mittal, A. K., Kaler, A., \& Banerjee, U. C. (2012). Free Radical Scavenging and Antioxidant Activity of Silver Nanoparticles Synthesized from Flower Extract of Rhododendron dauricum. Nano Biomedicine \& Engineering, 4(3).

18. Nabikhan, A., Kandasamy, K., Raj, A., \& Alikunhi, N. M. (2010). Synthesis of antimicrobial silver nanoparticles by callus and leaf extracts from saltmarsh plant, Sesuvium portulacastrum L. Colloids and surfaces B: Biointerfaces, 79(2), 488-493.

19. Tabassum, S., Asim, A., Khan, R. A., Arjmand, F., Rajakumar, D., Balaji, P., \& Akbarsha, M. A. (2015). A multifunctional molecular entity $\mathrm{Cu}$ II-Sn IV heterobimetallic complex as a potential cancer chemotherapeutic agent: DNA binding/cleavage, SOD mimetic, topoisomerase $\mathrm{I} \alpha$ inhibitory and in vitro cytotoxic activities. RSC Advances, 5(59), 47439-47450.

20. Vigneshwaran, N., Nachane, R. P., Balasubramanya, R. H., \& Varadarajan, P. V. (2006). A novel one-pot 'green'synthesis of stable silver nanoparticles using soluble starch. Carbohydrate research, 341(12), $2012-2018$. 